\title{
Effect of magnesium sulfate on anesthesia depth, awareness incidence, and postoperative pain scores in obstetric patients
}

\author{
A double-blind randomized controlled trial
}

Başak Altıparmak, MD, Nalan Çelebi, MD, Özgür Canbay, MD, Melike K. Toker, MD, Banu Kılıçarslan, MD, Ülkü Aypar, MD.

\begin{abstract}

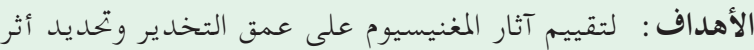

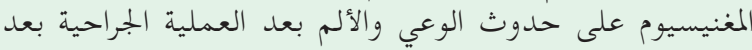
الولادة القيصرية .

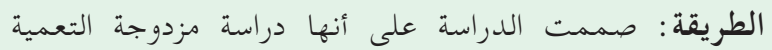

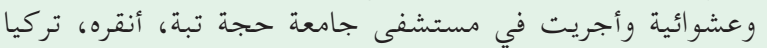

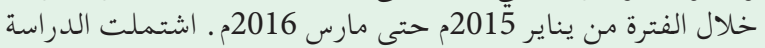

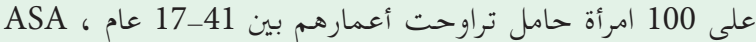

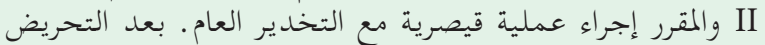

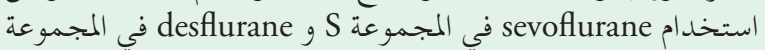

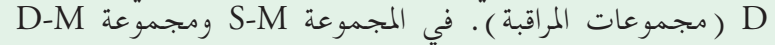

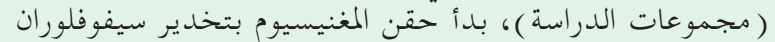

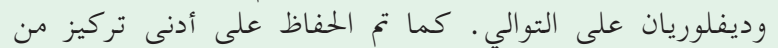

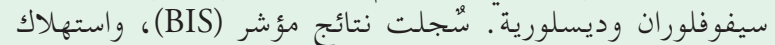

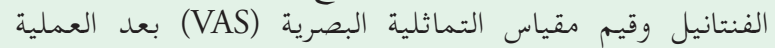

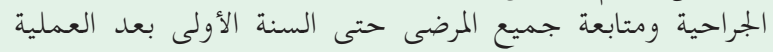
الجراحية للتوعية . احتراحية

النتائج: كانت المتغيرات الديمغرافية للمرضى مماثلة. كانتئ كانت قيم BIS

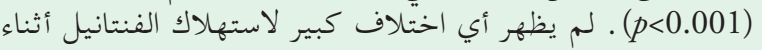

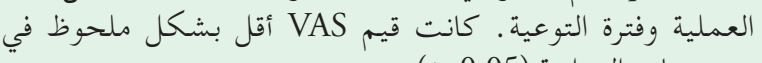

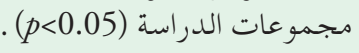

الحاتمة : ضخ المغنيسيوم يوفر قيم BIS أقل أثناء العمليات بشكل

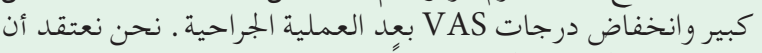

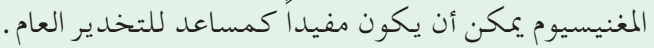

Objectives: To assess the effects of magnesium on the depth of anesthesia and to determine the effects of magnesium on incidence of awareness and postoperative pain after caesarean section.

Methods: The study was designed as a double-blind, controlled, randomized study and conducted in
Hacettepe University Hospital, Ankara, Turkey between January 2015 and March 2016. A total of 100 pregnant healthy women who were between 17 and 41 years old, ASA II, and scheduled for an elective cesarean section with general anesthesia were included in the study. After induction, sevoflurane was used for maintenance in Group S and desflurane in Group D (control groups). At Group S-M and Group D-M (study groups), magnesium infusion was started with sevoflurane and desflurane anesthesia respectively. Minimum alveolar concentration of sevoflurane and desflurane were kept constant. Bispectral index scores (BIS), fentanyl consumption and postoperative visual analogue scale (VAS) values were recorded. All of the patients had been followed-up for awareness until the postoperative first year.

Results: Demographic variables of the patients were similar. BIS values were significantly higher in control groups throughout the operation $(p<0.001)$. No significant difference was detected for intraoperative fentanyl consumption and awareness incidence. VAS values were significantly lower in study groups $(p<0.05)$.

Conclusion: Magnesium infusion provided significantly lower intraoperative BIS values and lower postoperative VAS scores. We believe that magnesium can be useful as an adjuvant to general anesthesia.

Saudi Med J 2018; Vol. 39 (6): 579-585

doi: 10.15537/smj.2018.6.22376

From the Department of Anesthesiology and Reanimation (Altiparmak, Toker), Muğla Sitkı Koçman University Training and Research Hospital, Muğla; and from the Department of Anesthesiology and Reanimation (Çelebi, Canbay, Killçarslan, Aypar), Hacettepe University, Ankara, Turkey.

Received 21st February 2018. Accepted 10th May 2018.

Address correspondence and reprint request to: Dr. Basak Altiparmak, Department of Anesthesiology and Reanimation, Training and Research Hospital, Muğla Sitkı Koçman University, Muğla, Turkey. E-mail: basak_ugurlu@yahoo.com; basakugurlu@me.com ORCID ID: https://orcid.org/0000-0002-8165-3438 
$M^{3}$ agnesium $(\mathrm{Mg})$ is widely used in anesthetic management. The element is known to attenuate stress responses to endotracheal intubation, preserve favorable hemodynamics, block acetylcholine releases at neuromuscular junctions, and potentiate the effects of nondepolarizing neuromuscular blockers. ${ }^{1}$ Moreover, studies found that magnesium sulfate reduces anesthetic requirements, shortens anesthetic induction with propofol and diminishes total postoperative analgesic consumption with no adverse maternal or neonatal effects. $^{2,3}$ Additionally, the element has potential analgesic and sedative properties; therefore, it is useful as an adjuvant during general anesthesia. ${ }^{4}$ Previous study ${ }^{5}$ have examined the effects of magnesium on anesthetic agent doses needed to keep bispectral index (BIS) values within fixed ranges. However, only a single pediatric study ${ }^{5}$ has evaluated the effect of intraoperative magnesium on BIS values while operation type and end-tidal anesthetic concentration were kept constant. This recent study had evaluated the depth of anesthesia only by intraoperative BIS values. Beside, the study was conducted in a completely different patient group. ${ }^{5}$ The term "awareness" is usually used to refer to an undesired condition in which a patient is under general anesthesia but conscious due to a stimulant; during awareness, the patient's brain stores information, and the patient may recall that information later. ${ }^{6}$ Most patients who experience awareness do not have long term postoperative complaints. ${ }^{7}$ However, some patients may have symptoms such as nightmares, daytime anxiety, and flashbacks, and in some rare cases, patients develop post-traumatic stress disorder. ${ }^{7,8}$ Over the last 20 years, the number of cesarean sections performed under regional anesthesia have significantly increased. Nonetheless, general anesthesia is used for cesarean sections due to emergencies, contraindications, or patient refusals of regional anesthesia; ${ }^{9}$ in those cases, low doses of general anesthetic agents are traditionally used. Thus, obstetric surgical patients have higher incidences of intra-operative awareness than other surgical patients, especially before deliveries. ${ }^{10}$

In this study, we aimed to assess the effect of magnesium infusion on the depth of anesthesia in adult obstetric patients. Our secondary aims were to assess the effects of magnesium on postoperative pain scores and incidence of awareness after cesarean section.

Disclosure. Authors have no conflict of interests, and the work was not supported or funded by any drug company.
Methods. After receiving ethical approval from the Hacettepe University Scientific Researches Assessment Committee (LUT-10/60), we conducted the study, in accordance with the Declaration of Helsinki, at Hacettepe University Hospital, Ankara, Turkey, between January 2015 and March 2016. We designed the study as prospective, randomized, controlled, and double blind. We obtained written informed consent from all patients. A total of 100 healthy pregnant women who preferred general anesthesia for cesarean section were included in the study. Patients were American Society of Anesthesiologists physical statu II, they were between 17 and 41 years old and all were scheduled for an elective cesarean section. Although none of the patients had any contraindication for regional anesthesia, they had preferred general anesthesia for their operations in the elective conditions. We followed up the patients for a year after the study using phone calls; this follow-up period ended in March 2017.

We excluded any patient with hyper magnesemia, any heart block, hypertension, diabetes mellitus, a pre-term pregnancy, multiple pregnancies, and preoperative fetal distress from the study.

Drug solutions for use in the study were prepared and labeled by an anesthesiologist, who did not participate in the study. The anesthesiologist was aware of the randomization table, prepared and labeled the drug solutions according to the related patient's weight. However, he did not participate in data collection or data analyzing. For bolus doses; $20 \mathrm{ml}$ sodium chloride and $20 \mathrm{ml}$ magnesium sulfate were placed into identical $20 \mathrm{~mL}$ syringes. Additionally, $500 \mathrm{~mL}$ of sodium chloride and an identical $500 \mathrm{~mL}$ of sodium chloride+magnesium sulfate were prepared for use in the study as intraoperative infusions.

Patients were randomly divided into 4 groups (S, D, S-M, and D-M) using a computer-generated randomization scheme, and each group included 25 patients. Then, we denoted 2 groups as control and 2 groups as study groups; consequently, 50 patients were considered control patients and 50 patients were study patients. Authors and patients were blinded to the group allocations.

In the operating room, we calculated each patient's electrocardiogram, non-invasive blood pressure, peripheral oxygen saturation, train of 4 (TOF), and BIS measurements. Each patient's TOF was measured using Datex-Ohmeda N-NMT Sensors (Helsinki, Finland), and each patient's BIS was measured using a Datex-Ohmeda S/5 monitor M-BIS module (Helsinki, Finland). During each operation, these measurements were monitored. 
Moreover, each patient had an airway assessment for possible difficulty with tracheal intubation and the assessment was documented before the anesthesia induction. Patients had $20-30^{\circ}$ head-up position to increase functional residual capacity. Then preoxygenation with $100 \% 02$ was applied by a face mask.

For all groups, 2 anesthesiologists performed inductions with $1-2 \mathrm{mg} \mathrm{kg}^{-1}$ of intravenous propofol, until each patient's BIS score decreased from 40-60, and $0.6 \mathrm{mg} \mathrm{kg}$ of intravenous rocuronium bromide. Endotracheal intubation was performed with a video laryngoscope as it usually provides a better view of the glottis than direct laryngoscope. If the first attempt of intubation failed, the second attempt was performed by the present anesthesiologist.

After the inductions, groups $\mathrm{S}$ and $\mathrm{D}$ received sevoflurane (Sevo) and desflurane (Des) as inhaled anesthetic agents, respectively. The groups received 20 $\mathrm{mL}$ of sodium chloride as a bolus dose in 15-20 seconds and then $500 \mathrm{~mL}$ of sodium chloride as intraperative infusion throughout the operation. These 2 groups were control groups. Similarly, groups S-M received Sevo and D-M received Des as inhaled anesthetic agents. However, they also received $30 \mathrm{mg} \mathrm{kg}^{-1}$ of magnesium sulfate, which was administered in 15-20 seconds using $20 \mathrm{~mL}$ syringes, and $10 \mathrm{mg} \mathrm{kg}^{-}$hour $^{-1}$ of magnesium sulfate as well as sodium chloride in the $500 \mathrm{~mL}$ of solutions as intraoperative infusion with a rate of $15 \mathrm{~mL} \mathrm{~kg}^{-1}$ hour ${ }^{-1}$. These 2 groups were the study groups.

To maintain anesthesia, we gave groups $S$ and S-M $1 \%$ end-tidal Sevo in 3 lt $\min ^{-1}$ of $40 \% \mathrm{O}_{2}$, and $60 \% \mathrm{~N}_{2} \mathrm{O}$. Similarly, we gave groups D and D-M 3\% end-tidal Des in 3 lt $\min ^{-1}$ of $40 \% \mathrm{O}_{2}$, and $60 \% \mathrm{~N}_{2} \mathrm{O}$. When a patient's heart rate or blood pressure increased more than $20 \%$ beyond the baseline values, we applied $1 \mathrm{mcg} \mathrm{kg}{ }^{-1}$ of intravenous fentanyl while keeping the patient's minimum alveolar concentration (MAC) constant. For all groups, we measured each patients' BIS values, mean arterial pressure (MAP), and heart rate before the anesthesia induction, immediately after the induction, and at $5 \mathrm{~min}$ intervals during the operation. We also recorded intraoperative opioid need of each patient.

When skin closure occurred, we stopped inhaled anesthetic agents and administered $0.1 \mathrm{mg} \mathrm{kg}^{-1}$ of atropine and $0.5 \mathrm{mg} \mathrm{kg}^{-1}$ of neostigmine to reverse the neuromuscular blockage. Each patient was extubated after their TOF ratio was $90 \%$ or higher. At $15 \mathrm{~min}$ before the end of each surgery, we administered $1,000 \mathrm{mg}$ of intravenous paracetamol to ensure postoperative analgesia, and in the ward, we applied $75 \mathrm{mg}$ of intramuscular diclofenac sodium every 8 hours until the end of second postoperative day. When a patient's visual analog scale (VAS) score was 4 or more, we administered $1 \mathrm{mg} \mathrm{kg}^{-1}$ of intravenous tramadol as a rescue analgesic. Moreover, we evaluated each patient 1 , 2 , and 24 hours after their operations using VAS scores.

As aforementioned, to objectively evaluate anesthesia depth, we assessed each patient for awareness under general anesthesia. After anesthesia induction, we played audio, chosen with the assistance of Hacettepe University's Medical Psychiatry Department, to each patient using earphones. The audio was a story that is included in the Wechsler memory scale; the story is used for neurophysiological examinations of patients, and it comprises 24 key words in a single sentence. ${ }^{11}$

Similar to previous studies, ${ }^{12,13}$ one anesthesiologist questioned each patient 1,6 , and 24 hours after the patient's operation, as well as at the end of the 1 st month and the end of the 1 st year. This was carried out to evaluate the long-term effects of general anesthesia. For the first interview, each patient was given some clues regarding the story, then asked whether they recalled anything. If a patient could recall 3 or more words, then awareness under general anesthesia was noted.

Besides the questions concerning the Wechsler memory scale story, we asked questions from a modified Brice interview, which are accepted as "gold-standard" for postoperative awareness screening. ${ }^{14}$ The question set comprised 5 simple questions that were defined by Brice et $\mathrm{a}^{15}$ and modified by Moerman et al. ${ }^{16}$ The questions were as follows: 1) Before you slept, what is the last thing you can recall? 2) When you woke up at the end of the surgery, what do you remember as the first thing? 3) Can you remember anything between the moment you slept and woke up from the surgery? 4) Did you have any dream during the operation? 5) Can you tell the most disturbing thing about your operation and anesthesia experience?

Statistical analysis. Calculation of the sample size was based on previous investigations conducted about the effects of magnesium sulfate on BIS values and propofol consumption. Assuming $\alpha$ error $=0.05$ (2-tailed) and $\beta \varepsilon \tau \alpha$ error $=0.1$, a sample size of 45 patients, allocated to one group, had a power of $90 \%$ in regards to determining a clinically significant difference of $5 \%$ (effect size $d$ was 0.6 ) between the paired measurements of BIS values of the groups to which we did and did not give magnesium infusions. The sample size was calculated using the software Power Analysis and Sample Size, version 12 (made by NCSS, located in Kaysville, Utah, United States of America). We conducted the statistical analysis using the software Statistical Package for Social Science, Version 17 (SPSS, Chicago, Illinois, USA). We evaluated all demographic data and peri-operative periods with a one-way analysis 
of variance. Moreover, we conducted a Tukey HSD test to make multiple comparisons between the groups, and to evaluate the patients' VAS values, we performed a non-parametric Kruskal Wallis test. Finally, we conducted a Chi-square test to compare the patients' analgesic needs, dreams, and memories. We considered a p-value of less than 0.05 statistically significant, and we defined all data as a mean \pm standard deviation $($ mean $\pm S D)$.

Results. As aforementioned, we included 100 patients in the study. Demographic variables and surgical characteristics were similar between the groups (Table $1 \&$ Table 2).

To analyze BIS values, 4 different time points were chosen: the first time point (BIS 0) was chosen to compare the baseline BIS values of the patients. The second time point (BIS 5) was chosen to assess the early effect of $\mathrm{Mg}$ bolus on BIS values. The third time point (BIS 20) was accepted as the mid-point of each operation. We reported the mean BIS values at the intraoperative 20 minute to provide an idea about the intraoperative BIS values of the patients during maintenance of anesthesia. The last time point (BIS End) was chosen to assess the effect of intraoperative $\mathrm{Mg}$ infusion.

The BIS 0 values were similar for all groups ( $p>0.05)$, but the BIS 5 values were significantly higher in the Sevo group $(p<0.001)$. The BIS 20 values of the control groups were significantly higher than the study groups $(p<0.001)$, and similar to each other $(p=0.519)$. Likewise, the BIS end values of the control groups were significantly higher than the study groups $(p<0.001)$, and similar to each other $(p=0.781)$. Similarly, there were no statistically significant differences between the study groups $(p=0.737)$. The comparison of BIS values between group Sevo and group Sevo $+\mathrm{Mg}$, and between group Des and group Des $+\mathrm{Mg}$ are summarized in Table 2. The BIS 5, BIS 20 and BIS end values were significantly lower in study groups.

There were no significant differences between the groups' MAPs and heart rates throughout the operations $(p>0.05)$. The comparison of hemodynamic parameters between group Sevo and group Sevo+Mg and between group Des and group Des $+\mathrm{Mg}$ are summarized in Table 3.

The intraoperative fentanyl consumption was similar between the groups. A total of 15 patients in group $S$, 14 patients in group D, 9 patients in group S-M, and 11 patients in group D-M received additional $1 \mathrm{mcg} \mathrm{kg}^{-1}$ of intravenous fentanyl bolus intraoperatively. There was no significant difference between the groups sevo and Sevo $+M g$, and between Des and Des+Mg $(p=0.093$ and
Table 1 - Patient's characteristics, operation time, and BIS values at different time-points between Sevo and Group Sevo+Mg groups.

\begin{tabular}{lccc}
\hline Variables & Sevo & Sevo $+\mathrm{Mg}$ & $P$-value \\
\hline Age (years) & $29.7 \pm 5.1$ & $30.2 \pm 5.8$ & 0.758 \\
Weight (kg) & $73.4 \pm 14.2$ & $77.5 \pm 11.8$ & 0.267 \\
Operation time (min) & $47.4 \pm 11.19$ & $44.8 \pm 7.96$ & 0.349 \\
BIS & $95.9 \pm 2.76$ & $95.3 \pm 2.88$ & 0.456 \\
BIS 0 & $50.8 \pm 7.8$ & $39.2 \pm 5.5$ & $<0.001$ \\
BIS 5 & $55.6 \pm 6.08$ & $40.9 \pm 7.4$ & $<0.001$ \\
BIS 20 & $64.8 \pm 7.5$ & $53.0 \pm 8.2$ & $<0.001$ \\
BIS end & Values are expressed as mean \pm SD. Sevo - sevoflurane, des - desflurane, \\
Mg - magnesium sulphate, BIS - bispectral index score, BIS 0 - BIS \\
value before induction, BIS 5 - BIS value 5 minutes after induction, BIS \\
\multicolumn{4}{c}{ 20 - BIS value 20 minutes after induction, } \\
BIS end - BIS value at the end of the operation \\
\hline
\end{tabular}

Table 2 - Patient's characteristics, operation time, and BIS values at different time-points between Des and Group Des+Mg groups.

\begin{tabular}{lccc}
\hline Variables & Des & Des $+\mathrm{Mg}$ & $P$-value \\
\hline Age (Year) & $30.2 \pm 4.3$ & $29.7 \pm 4.78$ & 0.735 \\
Weight (kg) & $79.9 \pm 14.7$ & $77.1 \pm 14$ & 0.501 \\
Operation time (min) & $46.28 \pm 5.8$ & $44.96 \pm 5$ & 0.389 \\
BIS & $95.2 \pm 3.05$ & $96.28 \pm 2.4$ & 0.191 \\
BIS 0 & $45.96 \pm 6.5$ & $35.96 \pm 5.1$ & $<0.001$ \\
BIS 5 & $52.6 \pm 7.1$ & $41.1 \pm 9.78$ & $<0.001$ \\
BIS 20 & $62.88 \pm 4.5$ & $50.88 \pm 8.3$ & $<0.001$ \\
BIS end & Values are expressed as mean \pm SD. Sevo - sevoflurane, Des - desflurane, \\
Mg - magnesium sulphate, BIS - bispectral index score, BIS 0 - BIS \\
value before induction, BIS 5 - BIS value 5 minutes after induction, \\
BIS 20 - BIS value 20 minutes after induction, BIS end - BIS value at \\
\multicolumn{4}{c}{ the end of the operation } \\
\hline
\end{tabular}

$p=0.401)$. The fentanyl consumption between control groups and study groups were similar $(p=0.307)$.

We asked the patients questions concerning their pain 1,2, and 24 hours after their operations. The study groups had significantly lower VAS scores at all time points than the control groups $(p<0.05)$. The comparison VAS scores between group Sevo and group $\mathrm{Sevo}+\mathrm{Mg}$ and between group Des and group Des $+\mathrm{Mg}$ are listed in Table 4.

During the postoperative interviews we performed at the end of the $1 \mathrm{st}, 6 \mathrm{th}$, and 24 th hours after the operations, one patient in group $S, 2$ patients in group $\mathrm{D}$, and one patient in group $\mathrm{D}-\mathrm{M}$ reported intraoperative dreams. Patients in group $S$ and one of the patients in group $\mathrm{D}$ stated that their dreams were about the surgery and the hospital. The other patients stated that their dreams were not related to their surgeries. At the end of the 1st post-operative month, the same 4 
Table 3 - Hemodynamic parameters between Group Sevo and Group Sevo+Mg and between Des and Group Des + Mg groups.

\begin{tabular}{|c|c|c|c|c|c|c|}
\hline \multirow[t]{2}{*}{ Parameters } & \multicolumn{2}{|r|}{ HR } & \multirow[t]{2}{*}{$P$-value } & \multicolumn{2}{|c|}{ MAP } & \multirow[t]{2}{*}{$P$-value } \\
\hline & Sevo & Sevo + Mg & & Sevo & Sevo $+\mathrm{Mg}$ & \\
\hline $0 \mathrm{~min}$ & $102 \pm 17.1$ & $105 \pm 16.6$ & 0.475 & $95.1 \pm 11.1$ & $91.3 \pm 71$ & 0.168 \\
\hline $5 \mathrm{~min}$ & $113.8 \pm 14$ & $111.4 \pm 12.9$ & 0.544 & $92.3 \pm 16.5$ & $84.9 \pm 12$ & 0.82 \\
\hline $20 \mathrm{~min}$ & $91.5 \pm 14.4$ & $96.7 \pm 18.3$ & 0.270 & $83.8 \pm 12.9$ & $84.9 \pm 12.5$ & 0.766 \\
\hline End & $93.8 \pm 14.8$ & $96.4 \pm 14.1$ & 0.537 & $88.1 \pm 15.6$ & $83.4 \pm 12.5$ & 0.241 \\
\hline Parameters & Des & Des + Mg & $P$-value & Des & Des + Mg & $P$-value \\
\hline $0 \min$ & $100.1 \pm 7.5$ & $103.0 .8 \pm 9$ & 0.214 & $92.3 \pm 11.5$ & $91.4 \pm 14.8$ & 0.800 \\
\hline $5 \mathrm{~min}$ & $106 \pm 18.3$ & $108.7 \pm 11.2$ & 0.586 & $86.9 \pm 13$ & $86.1 \pm 13.4$ & 0.832 \\
\hline $20 \mathrm{~min}$ & $88 \pm 16.9$ & $89.2 \pm 13.4$ & 0.768 & $83.2 \pm 14.5$ & $83.2 \pm 14.5$ & 0.982 \\
\hline End & $89.9 \pm 16.4$ & $89.2 \pm 10.2$ & 0.848 & $82.8 \pm 11.6$ & $85 \pm 12.3$ & 0.521 \\
\hline
\end{tabular}

Table 4 - Visual analogue scale (VAS) scores at different time-points between sevo and group sevo+Mg groups.

\begin{tabular}{lccc}
\hline VAS & Sevo & Sevo $+\mathrm{Mg}$ & $P$-value \\
\hline VAS 1 & $8.1 \pm 0.9$ & $7.1 \pm 0.6$ & $<0.001$ \\
VAS 2 & $5.1 \pm 0.6$ & $3.5 \pm 0.6$ & $<0.001$ \\
VAS 24 & $4.0 \pm 0.6$ & $3.0 \pm 0.6$ & $<0.001$ \\
\hline VAS & Des & Des $+\mathrm{Mg}$ & $P$-value \\
\hline VAS 1 & $8.1 \pm 0.8$ & $7.1 \pm 0.6$ & $<0.001$ \\
VAS2 & $4.8 \pm 0.8$ & $3.5 \pm 0.6$ & $<0.001$ \\
VAS24 & $3.8 \pm 0.7$ & $3 \pm 0.4$ & $<0.001$ \\
\hline
\end{tabular}

Values are expressed as mean \pm SD. Sevo - sevoflurane, $\mathrm{Mg}$ - magnesium sulphate, VAS 1 - VAS score at postoperative first hour,

VAS 2 - VAS score at postoperative second hour, VAS 24 - VAS score at postoperative 24th hour

patients still reported intraoperative dreams, but could not remember anything regarding the contents of their dreams. This difference was not statistically significant $(p=0.9)$ among the groups.

At end of the first postoperative year, no patients reported hearing any sounds during their operations or remembered anything concerning the surgeries. Moreover, no patients had significant answers to the modified Brice questions in regards to intraoperative awareness. Finally, no patients had any signs of posttraumatic stress disorder.

Discussion. The BIS values of the groups to which we administered $\mathrm{Mg}$ infusions were significantly lower than the BIS values of the groups in which we did not administered $\mathrm{Mg}$ infusions, and none of those patients were aware under general anesthesia. Similarly, the postoperative VAS scores of the groups in which we administered $\mathrm{Mg}$ infusions were significantly lower than the BIS scores of the groups in which we did not administered $\mathrm{Mg}$ infusions. However, there were no significant differences in the hemodynamic parameters and intraoperative opioid needs of the groups.

In general, practitioners consider BIS monitoring valuable and reliable for monitoring anesthesia depth, both for adult and pediatric patients. However, when considering the underlying mechanism of general anesthesia, hypnosis, as a single component of anesthesia, can not be used to define an overall anesthetic depth. ${ }^{17}$ Nonetheless, hypnotic depth is considered to be the primary endpoint of anesthesia, and it is the focus of contemporary anesthesia-depth monitoring. ${ }^{18}$ Therefore, in the current study we evaluated the central effects of $\mathrm{Mg}$ with BIS monitoring.

In the current literature, there are studies which have evaluated the effects of intraoperative $\mathrm{Mg}$ on intravenous and inhaled anesthetic doses, opioid demands, and muscle relaxant needs in regards to maintaining BIS values of 40-60. However, Amer et $\mathrm{al}^{5}$ have recently suggested that BIS values of 40-60 may be too wide to objectively evaluate the effects of $\mathrm{Mg}$ on anesthetic need. So, the researchers kept MAC values of inhaled anesthetic agents constant and used BIS scores for monitoring the effects of $\mathrm{Mg}$ in their study. Similarly, they found the BIS values of the group with $\mathrm{Mg}$ significantly lower than control group. ${ }^{5}$ Amer et $\mathrm{al}^{5}$ used only BIS monitoring to evaluate the effect of $\mathrm{Mg}$ on depth of anesthesia. However, we assessed the patients both with BIS monitoring and interviews to detect awareness. We followed up with the patients for a year and we conducted 5 interviews with each patient at different time points to evaluate the patients' awareness experiences under general anesthesia. Thus, we examined both the long-term and short-term central effects of Mg. Awareness under general anesthesia often occurs due to inadequate levels of anesthesia. ${ }^{19}$ As aforementioned, studies reported that serious 
psychological problems that lead to post-traumatic stress disorder can occur during the long term postoperative periods of patients who experience awareness. ${ }^{6}$ Moreover, intraoperative awareness also occurs when opioids and benzodiazepines, or weak anesthetics, such as nitrous oxide, are used separately or together. In contrast, inhaled anesthetics, such as Sevo, Des, isoflurane, as well as potent intravenous anesthetics, can successfully prevent intraoperative perceptions when they are used in proper concentrations. ${ }^{20}$ Despite this, many studies discussed intraoperative awareness that occurred with inhaled anesthetics. ${ }^{21,22}$ Considering this information, we hypothesized that adding an adjuvant agent to general anesthesia can increase anesthesia depth and prevent intraoperative awareness. We added $\mathrm{Mg}$ infusions to general anesthesia that comprised Sevo or Des, and none of our patients experienced awareness. Dreaming, which is related to awareness, was detected in 4 patients in different groups, but when we compared the groups, there were no statistically significant differences. Awareness under general anesthesia is a rare complication seen in $0.1 \%-0.2 \%$ of all patients. ${ }^{6}$ Some studies ${ }^{6,23}$ reported that these numbers can increase by $7 \%-28 \%$ in obstetric surgeries. Although we studied obstetric patients in the current study, this was not the case. The most likely reason is that our sample size was not large enough to detect awareness. Moreover, the constant and reasonable MAC values maintained throughout the operations likely prevented any awareness experiences. Moreover, we administered fentanyl to patients when their hemodynamic parameters increased more than $20 \%$ from their baseline values.

Lee et $\mathrm{al}^{24}$ compared different doses of $\mathrm{Mg}$ in study groups to a control group, and the researchers found that the BIS values of the study groups were significantly lower when $\mathrm{Mg}$ was administered through infusions. The BIS values of our study groups that received magnesium infusions were also significantly lower. This confirmation supports the hypothesis that $\mathrm{Mg}$ is a good adjuvant for general anesthesia. In addition, the BIS values of the study groups that received $\mathrm{Mg}$ infusions did not differ significantly. This suggests that Mg may increase anesthesia depth regardless of the inhaled anesthetic agent that is used. However, for the non-Mg groups, $5 \mathrm{~min}$ after induction, BIS values were higher when Sevo was used as the inhalation anesthetic agent. According to previous studies that were performed with similar inhaled anesthetics, this difference is not surprising. Different inhaled anesthetics that are given at different end-tidal concentration levels and have the same potencies can result in different BIS values. ${ }^{25}$ Jellish et $\mathrm{al}^{26}$ compared Sevo and Des and reported that BIS values were significantly lower in their Des group.
The mechanisms concerning the analgesic effects of magnesium sulfate are unclear, but calcium channel inhibition and $\mathrm{N}$-methyl-D-aspartate receptors are likely important. ${ }^{27}$ In some studies, bolus doses of $\mathrm{Mg}$ significantly reduced additional analgesic need. ${ }^{28}$ However, in our study, intraoperative fentanyl consumption did not significantly differ between the groups. This difference is likely due to different methodologies of the studies. For example, Gupta et $\mathrm{a}^{28}$ administered fentanyl in order to maintain BIS values of 40-60. In contrast, we administered fentanyl in response to hemodynamic changes. As there were no significant differences in the MAPs and heart rates of the patients, there were no significant differences in the patient's fentanyl consumption.

Magnesium sulphate infusion has been previously reported to reduce postoperative pain. ${ }^{29}$ Mireskandari et $\mathrm{al}^{29}$ evaluated the effects of preoperatively induced magnesium sulfate on postoperative pain in obstetric patients. They reported that administering intravenous bolus magnesium sulfate prior to inducing patients with general anesthesia can reduce postoperative VAS scores and the effects of morphine consumption during the first 24 hours. Similarly, the VAS scores of our $\mathrm{Mg}$ groups were significantly lower during the study period. However, Frassanito et $\mathrm{al}^{30}$ studied the effects of intravenous $\mathrm{Mg}$ infusions on postoperative pain in patients who under went total knee arthroplasties with spinal anesthesia. They found no significant differences in postoperative pain and analgesic consumption after the patients received intravenous magnesium sulfate infusions. Moreover, $\mathrm{Mg}$ is the focus of studies regarding postoperative inflammation. Previous study ${ }^{31}$ reported that the element significantly reduces postoperative sore throats related to endotracheal intubations. However, the exact mechanisms are unknown, as aforementioned, the attenuation effects of $\mathrm{Mg}$, in regards to inflammatory responses to surgery, may relate to low postoperative pain.

A significant limitation of our study was its relatively small sample size. We conducted a power analysis in order to obtain significant differences between paired BIS measurements, so the patient number we calculated was likely insufficient for detecting awareness. In order to obtain more objective data regarding awareness during general anesthesia, further studies with larger numbers of patients are necessary. However, conducting such studies is becoming increasingly difficult due to increased preferences for regional anesthesia over cesarean sections. A second limitation of the study is the lack of information about the propofol doses needed to decrease BIS values under 60 during induction of anesthesia. The data about propofol doses have might 
give an idea about the effect of bolus dose of $\mathrm{Mg}$ on anesthetic agent need.

In conclusion, $\mathrm{Mg}$ infusion resulted in significantly lower intraoperative BIS values and lower postoperative VAS scores than no $\mathrm{Mg}$ infusions. Thus, we believe that $\mathrm{Mg}$ is useful as an adjuvant for general anesthesia in cesarean section patients. However, a larger sample size is needed to properly assess awareness under general anesthesia.

Acknowledgment. We would like to thank Scribendi (www.scribendi.com) for English language editing.

\section{References}

1. Kutlesic MS, Kutlesic RM, Mostic-Ilic T. Magnesium in obstetric anesthesia and intensive care. J Anesth 2017; 31: 127-139.

2. Dean C, Douglas J. Magnesium and the obstetric anaesthetist. Int J Obstet Anesth 2013; 22: 52-63.

3. Do SH. Magnesium: a versatile drug for anesthesiologists. Korean J Anesthesiol 2013; 65: 4-8.

4. Barbosa FT, Barbosa LT, Juca MJ, Cunha RM. Applications of magnesium sulfate in obstetrics and anesthesia. Rev Bras Anestesiol 2010; 60: 104-110.

5. Amer MM, Abdelaal Ahmed Mahmoud A, Abdelrahman Mohammed MK, Elsharawy AM, Ahmed DA, Farag EM. Effect of magnesium sulphate on bi-spectral index (BIS) values during general anesthesia in children. BMC Anesthesiol 2015; 15: 126 .

6. Ghoneim MM, Block RI, Haffarnan M, Mathews MJ. Awareness during anesthesia: risk factors, causes and sequelae: a review of reported cases in the literature. Anesth Analg 2009; 108: $527-535$.

7. Leslie K, Chan MT, Myles PS, Forbes A, McCulloch TJ. Posttraumatic stress disorder in aware patients from the B-aware trial. Anesth Analg 2010; 110: 823-828.

8. Mashour GA. Posttraumatic stress disorder after intraoperative awareness and high-risk surgery. Anesth Analg 2010; 110: 668-670

9. Campbell J, Sultan P. Regional anaesthesia for caesarean section: a choice of three techniques. Br J Hosp Med (Lond) 2009; 70: 605.

10. Sebel PS, Bowdle TA, Ghoneim MM, Rampil IJ, Padilla RE, Gan TJ, Domino KB. The incidence of awareness during anesthesia: a multicenter United States study. Anesth Analg 2004; 99: 833-839.

11. Fujimori J, Nakashima I, Baba T, Meguro Y, Ogawa R, Fujihara $\mathrm{K}$. Cognitive impairment in neuromyelitis optica spectrum disorders: A comparison of the Wechsler Adult Intelligence Scale-III and the Wechsler Memory Scale Revised with the Rao Brief Repeatable Neuropsychological Battery. eNeurologicalSci 2017; 9: 3-7.

12. Elhakim M, Abdelhamid D, Abdelfattach H, Magdy H, Elsayed A, Elshafei M. Effect of epidural dexmedetomidine on intraoperative awareness and post-operative pain after one-lung ventilation. Acta Anaesthesiol Scand 2010; 54: 703-709.
13. Walker EMK, Bell M, Cook TM, Grocott MPW, Moonesinghe SR, Central SO, et al. Patient reported outcome of adult perioperative anaesthesia in the United Kingdom: a crosssectional observational study. Br J Anaesth 2016; 117: 758-766.

14. Mashour GA, Kent C, Picton P, Ramachandran SK, Tremper KK, Turner CR, et al. Assessment of intraoperative awareness with explicit recall: a comparison of 2 methods. Anesth Analg 2013; 116: 889-891.

15. Brice DD, Hetherington RR, Utting JE. A simple study of awareness and dreaming during anaesthesia. Br J Anaesth 1970; 42: 535-542.

16. Moerman N, Bonke B, Oosting J. Awareness and recall during general anesthesia. Facts and feelings. Anesthesiology 1993; 79: 454-464.

17. Campagna JA, Miller KW, Forman SA. Mechanisms of actions of inhaled anesthetics. N Engl J Med 2003; 348: 2110-2124.

18. Bruhn J, Myles PS, Sneyd R, Struys MM. Depth of anaesthesia monitoring: what's available, what's validated and what's next? Br J Anaesth 2006; 97: 85-94.

19. Ghoneim MM. Awareness during anesthesia. Anesthesiology 2000; 92: 597-602.

20. Kuo PJ, Lee CL, Wang JH, Hsieh SY, Huang SC, Lam CF. Inhalation of volatile anesthetics via a laryngeal mask is associated with lower incidence of intraoperative awareness in non-critically ill patients. PloS One 2017; 12: e0186337.

21. Kino A, Nakamura K. [Awareness during general anesthesia for head and neck surgery--a case report]. Masui The Japanese Journal of Anesthesiology 2011; 60: 241-243. Japanese

22. Russell IF. Unreported paediatric awareness during surgery. Anaesthesia 2016; 71: 590-591.

23. Paech MJ, Scott KL, Clavisi O, Chua S, McDonnell N, Group AT. A prospective study of awareness and recall associated with general anaesthesia for caesarean section. Int J Obstet Anesth 2008; 17: 298-303.

24. Lee DH, Kwon IC. Magnesium sulphate has beneficial effects as an adjuvant during general anaesthesia for caesarean section. Br J Anaesth 2009; 103: 861-866.

25. Samarkandi AH. The bispectral index system in pediatrics-is it related to the end-tidal concentration of inhalation anesthetics? Middle East J Anesthesiol 2006; 18: 769-778.

26. Jellish WS, Owen K, Edelstein S, Fluder E, Leonetti JP. Standard anesthetic technique for middle ear surgical procedures: a comparison of desflurane and sevoflurane. Otolaryngol Head Neck Surg 2005; 133: 269-274.

27. Miranda HF, Bustamante D, Kramer V, Pelissier T, Saavedra H, Paeile C, Fernandez E, Pinardi G. Antinociceptive effects of Ca2+ channel blockers. Eur J Pharmacol 1992; 217: 137-141.

28. Gupta SD, Mitra K, Mukherjee M, Roy S, Sarkar A, Kundu $S$, et al. Effect of magnesium infusion on thoracic epidural analgesia. Saudi J Anaesth 2011; 5: 55-61.

29. Mireskandari SM, Pestei K, Hajipour A, Jafarzadeh A, Samadi S, Nabavian O. Effects of preoperative magnesium sulphate on post-cesarean pain, a placebo controlled double blind study. $J$ Family Reprod Health 2015; 9: 29-33.

30. Frassanito L, Messina A, Vergari A, Colombo D, Chierichini A, Della Corte F, et al. Intravenous infusion of magnesium sulfate and postoperative analgesia in total knee arthroplasty. Minerva Anestesiol 2015; 81: 1184-1191.

31. Yadav M CN, Gopinath R: Effect of magnesium sulfate nebulization on the incidence of postoperative sore throat. $J$ Anaesthesiol Clin Pharmacol 2016; 32: 168-171. 